\title{
High-salt intake during pregnancy may influence the outcome of renal ischemia/reperfusion in in adult offspring
}

\author{
Felora Shahzamani ${ }^{1,2}$, Ramesh Monajemi' ${ }^{2}$, Mehdi Nematbakhsh ${ }^{1,3,4^{*}}$ \\ ${ }^{1}$ Water and Electrolytes Research Center, Isfahan University of Medical Sciences, Isfahan, Iran \\ ${ }^{2}$ Department of Biology, Falavarjan Branch, Islamic Azad University, Isfahan, Iran \\ ${ }^{3}$ Department of Physiology, Isfahan University of Medical Sciences, Isfahan, Iran \\ ${ }^{4}$ Isfahan ${ }^{\mathrm{MN}}$ Institute of Basic and Applied Sciences Research, Isfahan, Iran
}

\section{A R T I C L E I N F O}

Article Type:

Brief Communication

\section{Article History:}

Received: 29 July 2017

Accepted: 1 November 2017

Published online: 8 December 2017

Keywords:

Salt diet

Pregnancy

Offspring

Ischemia/reperfusion

\begin{abstract}
A B S T R A C T
Introduction: The salt diet during the pregnancy may disturb the adult offspring's organs functions.

Objectives: This study was designed to determine the role of high salt intake during pregnancy on the outcome of renal ischemia reperfusion (IR) in adult offspring.

Materials and Methods: Renal IR was induced in 55 adult male and female offspring from mothers who intake high salt or normal drinking water during pregnancy, and the kidney function was evaluated.

Results: Salt intake during pregnancy increased the serum levels of creatinine $(\mathrm{Cr})$ and blood urea nitrogen $(\mathrm{BUN})$ and decreased creatinine clearances $(\mathrm{ClCr})$ level in offspring after renal IR gender dependently.

Conclusion: The structural change in kidney of offspring from mothers who were subjected to salt intake during pregnancy may influence the outcomes of offspring's kidney functions after renal IR.
\end{abstract}

\section{Implication for health policy/practice/research/medical education}

The structural change in kidney of offspring form mothers who were subjected to salt intake during pregnancy may influence the outcomes of offspring's kidney functions after renal ischemia reperfusion (I/R).

Please cite this paper as: Shahzamani F, Monajemi R, Nematbakhsh M. High-salt intake during pregnancy may influence the outcome of renal ischemia/reperfusion in in adult offspring. J Renal Inj Prev. 2018;7(2):69-72. DOI: 10.15171/jrip.2018.17.

\section{Introduction}

High salt diet during pregnancy may alter some physiological functions and organs developments (1-5). Milk content may also change with high salt diet (6), and the offspring from mothers that received high salt diet during pregnancy demonstrated a higher blood pressure $(3,7)$. It is well-known that renin secrets by glomerular cells which are salt sensitive and high salt diet disturb renin secretion in offspring and may develop hypertension (8). Previously we demonstrated that cardiovascular response to angiotensin II in offspring subjected to high salt intake during pregnancy was altered gender dependently (9). Renal ischemia reperfusion (I/R) as a major cause of kidney disorder influences renin-angiotensin system (RAS) $(10,11)$ which may alter by type of diets during pregnancy $(7,12)$.

\section{Objectives}

This study was designed to find the role of high salt intake during pregnancy on the outcome of renal IR in adult offspring.

Materials and Methods

Animals

Female Wistar rats were subjected to tap water or high-salt water (2\%) during mating until delivery. At the 30th days 
of life (day of weaning) the offspring were assigned into eight groups, and they were housed to gain weight in 3-4 months.

Groups 1 to 4 called "water" groups included two groups of male (groups 1 and 2) and two groups of female (groups 3 and 4) offspring from mothers who received tap water during mating and pregnancy.

Groups 5 to 8 called "salt" groups included two groups of male (groups 5 and 6) and two groups of female (groups 7 and 8) offspring from mothers who received $2 \%$ salt in drinking water during mating and pregnancy.

\section{Experimental protocol}

At the day of experiment the adult offspring in groups 1 (male: $227 \pm 9 \mathrm{~g}, \mathrm{n}=8$ ), 3 (female: $169 \pm 4 \mathrm{~g}, \mathrm{n}=6$ ), 5 (male: $260 \pm 9 \mathrm{~g}, \mathrm{n}=7$ ) and 7 (female: $192 \pm 8 \mathrm{~g}, \mathrm{n}=7$ ) were anesthetized with chlorohydrate $(450 \mathrm{mg} / \mathrm{kg}$ i.p). The kidneys were prepared for vessels clamping, and the vessels were clamped for a period of 45 minutes, and afterwards the rats were subjected to 24 hours reperfusion. These groups were assigned as I/R groups.

The same procedures were applied to the animals from group 2 (male: $234 \pm 10 \mathrm{~g}, \mathrm{n}=8$ ), 4 (female: $167 \pm 6 \mathrm{~g}, \mathrm{n}=7$ ), 6 (male: $260 \pm 8 \mathrm{~g}, \mathrm{n}=7$ ) and 8 (female: $180 \pm 7 \mathrm{~g}, \mathrm{n}=5$ ), but the renal vessels were not clamped. These groups were considered as control (sham operated) groups. All the animals were subjected to urine collection during last 6 hours of reperfusion by keeping animals in standard metabolic cages to determine creatinine clearances $(\mathrm{ClCr})$. At the end of reperfusion, blood samples were obtained, and the animals were sacrificed humanly. The kidneys were removed and weighed rapidly.

The serum levels of creatinine (Cr), blood urea nitrogen (BUN), and nitrite (by Griess method) were measured. The $\mathrm{ClCr}$ was determined by the following $\mathrm{ClCr}$ formula. $\mathrm{ClCr}=\mathrm{UFx}_{\mathrm{Cr}} / \mathrm{P}_{\mathrm{Cr}}$ where $\mathrm{UF}(\mathrm{mL} / \mathrm{min}), \mathrm{U}_{\mathrm{Cr}}$ and $\mathrm{P}_{\mathrm{Cr}}$ stand for urine flow, urine $\mathrm{Cr}$ level and serum $\mathrm{Cr}$ concentration.

\section{Ethical issues}

The research followed the tenets of the Declaration of Helsinki. This project was approved by Ethics Committee of Isfahan University of Medical. Prior to the experiment, the protocols were confirmed to be in accordance with the guidelines of Animal Ethics Committee of Isfahan University of Medical Sciences (Ethical code \#IR.MUI. REC.1394.2.242).

\section{Statistical analysis}

Data are presented as mean \pm standard error of the mean (SEM). The comparison between every two groups was performed using student's independent $t$ test. A value of $P \leq 0.05$ was considered as significant.

\section{Results}

The serum levels of BUN and $\mathrm{Cr}$ increased by renal $\mathrm{I} / \mathrm{R}$, however these parameters in "salt" intake groups
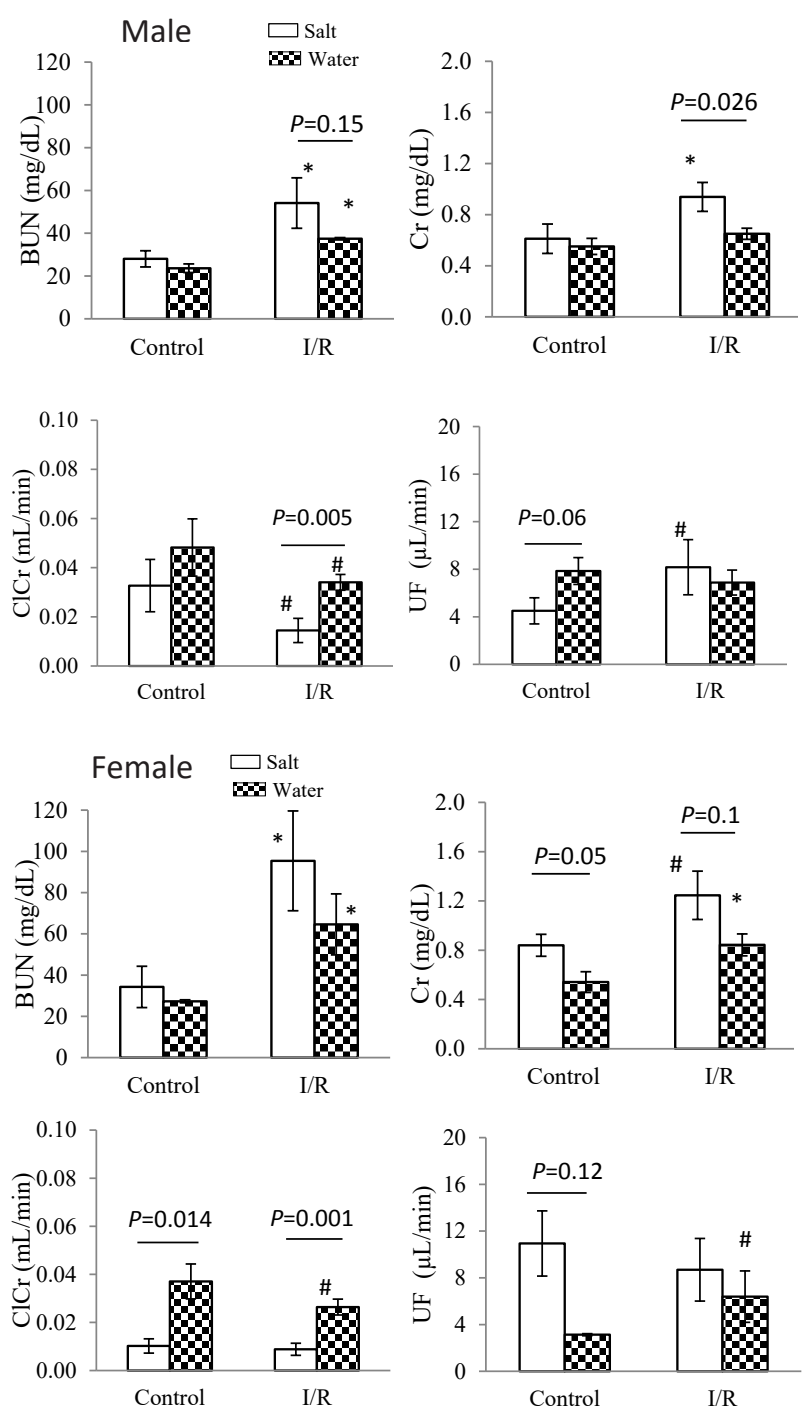

Figure 1. The kidney function parameters in 8 groups of experiments. I/R stands for ischemia/reperfusion. Significant difference from control group in similar diet $\left({ }^{*} P<0.05\right.$; \# $\left.P<0.2\right)$. Line and $p$ value on above indicated difference between the groups.

increased more than "water" intake groups (Figure 1). The lower $\mathrm{ClCr}$ was obtained in "salt" groups of male and female when compared with "water" intake groups by renal I/R $(P<0.05$, Figure 1$)$. In general, the level of BUN and $\mathrm{Cr}$ were higher and the level of $\mathrm{ClCr}$ was lower in "salt" groups when compared with "water" groups after renal $I / R$, and these parameters were different between genders. The kidney weight (KW) was increased by renal $\mathrm{I} / \mathrm{R}$, but the body weight change $(\Delta \mathrm{W})$ induced by renal $\mathrm{I} / \mathrm{R}$ was not significantly different between the renal $\mathrm{I} / \mathrm{R}$ and control groups (Table 1). Finally, the serum nitrite level was increased by $\mathrm{I} / \mathrm{R}$ in male salt group $(P<0.05)$

\section{Discussion}

The major findings of this research demonstrated that salt intake by mothers during pregnancy may influence the 
Table 1. The data for body weight (BW) change during 24 hours reperfusion $(\Delta \mathrm{W})$, kidney weight per $100 \mathrm{~g}$ of body weight (KW) and serum level of nitrite after 24 hours of reperfusion

\begin{tabular}{|c|c|c|c|c|c|c|c|c|}
\hline \multirow{3}{*}{ Parameter } & \multicolumn{4}{|c|}{ Male } & \multicolumn{4}{|c|}{ Female } \\
\hline & \multicolumn{2}{|c|}{ Salt } & \multicolumn{2}{|c|}{ Water } & \multicolumn{2}{|c|}{ Salt } & \multicolumn{2}{|c|}{ Water } \\
\hline & Control & I/R & Control & I/R & Control & I/R & Control & I/R \\
\hline$\Delta \mathrm{W}(\mathrm{g})$ & $-12.6 \pm 3.5$ & $-11.6 \pm 2.9$ & $-13.2 \pm 2.3$ & $-11.7 \pm 2.7$ & $2 \pm 3.5$ & $-6.6 \pm 2.8$ & $-9.5 \pm 4.5^{\dagger}$ & $-8.3 \pm 0.9$ \\
\hline KW (g/100 g BW) & $0.802 \pm 0.055$ & $0.950 \pm 0.046^{*}$ & $0.817 \pm 0.038$ & $0.919 \pm 0.057 \#$ & $0.860 \pm 0.023$ & $0.994 \pm 0.073 *$ & $0.809 \pm 0.002 \dagger$ & $0.906 \pm 0.092$ \\
\hline Nitrite ( $\mu \mathrm{mole} / \mathrm{l})$ & $4.81 \pm 1.17$ & $9.79 \pm 4.05^{*}$ & $6.92 \pm 1.65$ & $7.90 \pm 1.68$ & $8.10 \pm 1.74$ & $13.86 \pm 5.51$ & $6.91 \pm 1.62$ & $6.96 \pm 1.04$ \\
\hline
\end{tabular}

Significant difference from control group $\left({ }^{*} \mathrm{P}<0.05, \# \mathrm{P}<0.2\right)$. + Significant difference from control in salt group $(\mathrm{P}<0.05)$

outcome of kidney functions of offspring after renal I/R gender dependently. The offspring from mothers received salt diet during pregnancy performs a higher blood pressure $(3,7)$, and the RAS in offspring also influences by salt intake during pregnancy $(12,13)$. It also is reported that salt diet during pregnancy alters the kidney structures of offspring $(4,7,14)$, and therefore this alteration may affect the adult offspring's kidney function. Our data indicated a higher mean value for BUN and $\mathrm{Cr}$ and a lower value for CLCr levels in "salt" group after renal I/R when compared with "water" groups, while mean value of these parameters were different significantly between genders. A lower UF was detected in offspring male from mothers who were subjected to salt intake during pregnancy (12) while a higher UF in male and a lower UF in female response to angiotensin II infusion were found in such offspring (9). The UF is a major parameter to determine the CLCr, and therefore the alteration of $\mathrm{ClCr}$ is expected. The $\mathrm{KW}$ increased by renal I/R, and according to our data it seems that KW was gained more in "salt" groups compared to "water" groups after renal I/R. Previously we found that KW alteration response to angiotensin II infusion was different in "salt" and "water" groups of offspring in male but not in female (9).

\section{Conclusion}

It is concluded that structural change in kidney of offspring from mothers who were subjected to salt diet during pregnancy may influence the outcomes of offspring's kidney functions after I/R.

\section{Authors' contribution}

FS performed experimental procedures and helped in data analysis. MN designed, supervised the study, performed data analysis and prepared the final draft of the article.

\section{Conflicts of interest}

The authors declare no competing interests.

\section{Ethical considerations}

Ethical issues (including plagiarism, misconduct, data fabrication, falsification, double publication or submission, redundancy) have been completely observed by the authors.

\section{Funding/Support}

This research was supported by Isfahan University of Medical Sciences (grant \# 294242). We would like to thank Ms Z. Pezeshki and F. Eshraghi-Jazi for their assistances.

\section{References}

1. Barron LA, Giardina JB, Granger JP, Khalil RA. Highsalt diet enhances vascular reactivity in pregnant rats with normal and reduced uterine perfusion pressure. Hypertension. 2001;38:730-5.

2. Aloamaka CP, Ezimokhai M, Osman NA, Morrison J. The mechanism of relaxation in response to magnesium by the aorta of pregnant rats with salt-induced hypertension. Exp Physiol. 1995;80:79-87.

3. Hazon N, Parker C, Leonard R, Henderson IW. Influence of an enriched dietary sodium chloride regime during gestation and suckling and post-natally on the ontogeny of Hypertension in the rat. J Hypertens. 1988; 6:517-24.

4. Marin EC, Balbi AP, Francescato HD, Alves da Silva CG, Costa RS, Coimbra TM. Renal structure and function evaluation of rats from dams that received increased sodium intake during pregnancy and lactation submitted or not to 5/6 nephrectomy. Ren Fail. 2008;30:547-55. doi: $10.1080 / 08860220802060448$

5. Cardoso HD, Cabral EV, Vieira-Filho LD, Vieyra A, Paixão $A D$. Fetal development and renal function in adult rats prenatally subjected to sodium overload. Pediatr Nephrol. 2009;24:1959-65. doi: 10.1007/s00467-009-1247-1.

6. Vijande M, Brime JI, López-Sela P, Costales M, Argüelles J. Increased salt preference in adult offspring raised by mother rats consuming excessive amounts of salt and water. Regul Pept. 1996;66:105-8.

7. Coimbra TM, Francescato HD, Balbi AP, Marin EC, Costa RS. Renal development and blood pressure in offspring from dams submitted to high-sodium intake during pregnancy and lactation. Int J Nephrol. 2012;2012:919128. doi: 10.1155/2012/919128.

8. Provagna AJ, Beierwaltes WH, Rossi NF. effects of highsalt diet during pregnancy on fetal nephrogenesis and hypertension later in life: aberrant renin-angiotensin system programming. Ann Clin Exp Hypertension. 2016, 4:1-8.

9. Pezeshki Z, Eshraghi-Jazi F, Nematbakhsh M. Vascular response to graded angiotensin II Infusion in offspring subjected to high-salt drinking water during pregnancy: the effect of blood pressure, heart rate, urine output, endothelial permeability, and gender. Int J Vasc Med. 2014; 2014:876527. doi: 10.1155/2014/876527.

10. Maleki M, Nematbakhsh N. Gender difference in renal 
blood flow response to angiotensin II administration after ischemia/reperfusion in rats: the role of AT2 receptor. Adv Pharmacol Sci. 2016;2016:7294942. doi: 10.1155/2016/7294942.

11. Moslemi F, Taheri P, Azimipoor M, Ramtin S, Hashemianfar $\mathrm{M}$, Momeni-Ashjerdi A, et al. Effect of angiotensin II type 1 receptor blockade on kidney ischemia/reperfusion; a gender-related difference. J Renal Inj Prev. 2016;5:140-3. doi: $10.15171 /$ jrip.2016.29.

12. Mao C, Liu R, Bo L, Chen N, Li S, Xia S, et al. High-salt diets during pregnancy affected fetal and offspring renal renin-angiotensin system. J Endocrinol. 2013;218:61-73. doi: 10.1530/JOE-13-0139.

13. Alves-Rodrigues EN, Veras MM, Rosa KT, de Castro I, Furukawa LN, Oliveira IB, et al. Salt intake during pregnancy alters offspring's myocardial structure. Nutr Metab Cardiovasc Dis. 2013;23:481-6. doi: 10.1016/j. numecd.2011.10.006.

14. Koleganova N, Piecha G, Ritz E, Becker LE, Müller A, Weckbach M, et al. Both high and low maternal salt intake in pregnancy alter kidney development in the off spring. Am J Physiol Renal Physiol. 2011;301:F344-54. doi: 10.1152/ajprenal.00626.2010.

Copyright (c) 2018 The Author(s); Published by Nickan Research Institute. This is an open-access article distributed under the terms of the Creative Commons Attribution License (http://creativecommons.org/licenses/by/4.0), which permits unrestricted use, distribution, and reproduction in any medium, provided the original work is properly cited. 